\title{
Personal Development Planning and the Economics Tribe
}

Dr Anne Lee

University of Surrey

\begin{abstract}
The experience of outsourcing personal development planning (PDP) for first-year economics students to a central team is examined in the context of a research-led university. A pilot programme running PDP as a conference for 120 students was evaluated. The process suggests that there are differences between tutor and student perceptions which can be usefully addressed, especially the issue of developing conceptual understanding. The prevailing pedagogy of economics is reviewed to try to illuminate some of the barriers towards introducing PDP.
\end{abstract}

\section{Introduction}

Is economics as a discipline ready for personal development planning? We suggest that PDP is an holistic process, about the whole student's development. This paper addresses the question of whether discipline specialists need to be involved in this process or whether it can be 'outsourced'. We look at the early stages of introducing PDP in a research-led university economics department and ask whether there are any aspects of pedagogy in economics that helped or hindered this process.

\section{Defining personal development planning}

There is no universally recognised definition of what personal development planning (PDP) really is (Brennan and Shah, 2003). Universities were asked to develop progress files:'a means by which students can monitor, build and reflect upon their personal development' (Dearing, 1997). 
The UK national Quality Assurance Agency (QAA) guidelines state that PDP is concerned with learning in a holistic sense (both academic and non-academic) and a'process that involves self-reflection, the creation of a personal record, planning and monitoring progress towards the achievement of personal objectives.'The guidelines also give statements as to the intended purpose of PDP, i.e. to enable students to become more effective, independent and confident self-directed learners, to understand how they are learning, to relate their learning to a wider context and to improve their general skills for study and career management.

Discipline specialists may feel that their involvement in PDP is inappropriate because they lack the necessary skills to properly promote it; their job descriptions and expertise focus them on teaching their academic subject and being active researchers. Moreover economics staff said that they perceived high opportunity costs for investing their time in, as yet, unproven benefits from PDP. One senior member of the economics staff added 'the potential gains for students of PDP are difficult to identify being inextricably linked to personality and other factors in students' lives that are beyond the remit and control of their tutors. People trained in skills development and academic support are more likely to be able to capitalise on these possible benefits by developing latent talents.'

Allen describes PDP as a subtle revolution (2002: 2). The question is whether and to what extent specialist involvement is required.

A core strand of PDP is to encourage meta-learning.'Meta-learning is basically about a process of being aware and taking control of one's own learning' (Meyer and Shanahan, 2004:444). Universities are now being asked to make sure that students acquire the skills of self-management and lifelong learning, rather than just hoping that students will pick them up (Allen, 2002). Metacognition is the skill of directing how we think, and reframing is an important part of this skill. Barnett (2000) points out that we are educating our students in an age of supercomplexity and argues that the only skills that will count are the skills of constant inquiry, scrutiny and reframing. In this context I am using the concept of reframing as Habermas (1971) would describe reflection - the process of theory building. This is an important concept, which became highlighted in our survey of what economics lecturers were looking for in a top economics graduate, and that was missing from the first-year students' views.

\section{PDP at the University of Surrey}

Within an overall understanding there is considerable freedom to define PDP. At Surrey there was wide consultation, through a task group, on a framework that 
defined learning objectives and target outcomes and took into account the already agreed Surrey Skills Statement (see Appendix 1).

The learning objectives needed to reflect various perspectives: those of the university itself, academics, students and employers. There is an interesting (and separate) debate to be had about whose perspectives should take primacy. The learning objectives finally agreed upon are shown in Appendix 2 (Table 2). They were derived from an analysis of the university's mission statement and other policy documents, the work of Barrie at the University of Sydney on Graduate Attributes (2006) - see Appendix 2 (Table 3) - and work looking at the stages of maturation that graduates and adults may move through (Perry, 1970; Hall, 1994).

Perry (1970) wrote about the stages he identified that students at Harvard went through during their college years. This study has been criticised for being dated and gender specific (mostly male), but later studies have replicated condensed versions of these stages. Perry found that students move from an understanding of knowledge, which is a basic duality (there is a right and a wrong), through perceiving relativism to understanding the role of reflection and self-identity.

Perry emphasised the students' initial desire for certainty, for facts and a belief that the teacher will know them, moving to the development of a conceptual and provisional attitude towards knowledge. This development of conceptual understanding is an area in which we later demonstrate that new economics undergraduates may have a void.

Hall (1994) emphasised the move to situate understanding in a holistic world view. He wrote about the different values that adults may have as they examine them: moving from surviving through self-initiating to interdepending. This highlights the need for a developmental approach and suggests that the development of a coherent value system will underpin any effective PDP.

The University of Surrey has a vibrant professional placement scheme for undergraduate students and an excellent record on graduate employment. Thus as an institution it emphasises and values employability as a key part of PDP.

The framework of learning objectives chosen by Surrey was similar to that designed by Sydney, but the implications of the words within the framework were different. It was agreed that the learning objectives should cover three main areas:

1 Learning, research and scholarship

2 Employability and engagement with society

3 Personal and communication skills. 
The institutional policy implies that the departments are responsible for deciding how they want PDP delivered and what activities are to be included. The subsequent implication is that there should be an audit trail available so that the PDP process can be evaluated.

Appendix 2 lists the learning objectives for first-year students at Surrey and the objectives identified by Sydney's graduate attributes project.

\section{Economics and PDP?}

The Economics Department wanted to find some way of offering PDP to their students. It had limited spare staff capacity or skill in this area and economics staff had been less involved than some other departments in the evolving task group discussions about PDP.

Whilst it was wise to be considering PDP at this stage, the Economics Department did not have to. Thus it was demonstrating some interest in 'emphasising educating the whole student' and testing the ground for when PDP became compulsory. What did the department do and how did it do it?

In consultation with staff in the central academic and student support department, the economics team examined various possible approaches. The university policy was that departments could choose to implement PDP through personal tutorials and/or embed it within modules - two options not attractive to economics staff for reasons outlined below.

In the central team we faced two questions:

1 How could we support economics staff in their search to deepen their understanding of the concept of PDP and find cost-effective methods of delivery?

2 How could we support them in making it available to their students?

Whilst economics has historically been classified as a social science (and therefore a 'soft, applied' subject according to Biglan (1973a)), mathematics has become an increasingly important part of the subject. In fact Becher and Trowler (2001) argue that the subject shares 'one common frontier with mathematics and another with political science; some trade relations with history and sociology; and a lesser measure of shared ground with psychology, philosophy and law' (p. 59).

The range of interests identified and the requirements for conceptual understanding supports Becher and Trowler's identification of political science, history, sociology, psychology, philosophy and law as linked to economics. The 
interesting part of this list (in terms of discipline analysis) is the absence of the physical sciences. Biglan (1973b) said 'scholars in social science emphasie educating the whole student and evidence a more personal commitment to students than do those in physical sciences' (p. 205).

Mathematics also appeared as a highly rated skill for the top economics graduate. Biglan (1973a) includes maths (along with the physical sciences, geology and astronomy) as a pure non-life system hard subject (p. 207). This suggests that economics is on the cusp of both the hard and soft subjects and that economics students do need a broad interest and a wide range of conceptual abilities to be able to study successfully, as well as skills in pure maths and quantitative analysis.

We looked to see if there is any supporting evidence for the omnipresence of the economics textbook (and lack of presence of journal articles) identified as a feature of economics by Richardson (2004).

One of the economics staff commented on textbooks, 'I think they are increasingly popular because, firstly it is now accepted (for good or ill) that there is a core of economic principles, and because these (and their extensions) are increasingly being discussed in the journals in rather mathematical ways. Textbooks distil these developments, link them back to basics and, I think, can help prevent the fragmentation of the discipline. Many of our textbooks are written by top theorists and I sometimes wonder whether they also seek this unifying goal (as well as shedloads of cash!).'

Thus the economics staff faced several difficulties in introducing PDP:

1 They had not been involved in the early task group discussions, and the demands being made on them felt new and additional to previous requirements

2 Their priority in a research-led university was to deliver high-quality published work.

3 As the discipline itself moves to becoming a 'hard pure' subject there is intrinsically less emphasis on educating the whole student.

4 They felt a lack of expertise in PDP: their academic training made them expert economists by profession.

\section{The chosen intervention}

In the absence of a binding requirement to deliver PDP there was little economics staff commitment to organising additional tutorials or to develop assessed modules. The options for working towards offering PDP opportunities that would enable personal growth and increased self-awareness for the students were limited. 
The solution that was accepted for 2006 was one offered by the university's central academic support unit. It involved running a short separate module that was based around a conference, a taught session on information retrieval and a follow-up assignment. Economics staff approved, saying that this model reflected 'economies of scale'.

The cohort of 120 first-year students was divided into two groups and a conference was held in the university's main teaching block on two consecutive Fridays. To meet the QAA requirement of introducing students to PDP support from outside the academic curriculum (the students union, the language centre, careers, etc.) various university groups were invited to mount stands.

The conference was a mixture of short lectures, exercises and discussion groups. It covered the characteristics of a top economics student, approaches to learning and academic writing. A second, later session included an exercise on accessing materials from the library and via the internet. The organisation of the conference required little time from the economics staff, though considerable time from the central team

In one fell swoop the Economics Department fulfilled the university's minimum requirements for providing PDP opportunities for its graduates. There were also opportunities created for building upon this initiative throughout the year. Students were asked to submit a 1,500-word assignment and the marked assignments were handed back by personal tutors. The assignment asked the students to reflect on the differences between learning at school and at university and to identify what steps they would take to become a top economics graduate.

With the support of the Head of the Economics Department, one aim of the conference was to deepen students' understanding of what was required in an outstanding economics graduate. An email survey of half a dozen of the economics staff was conducted. They were asked to list the characteristics they thought were most important. This yielded a series of requirements which were synthesised and the results were fed back to staff for further evaluation. A discourse analysis identified their view of the key characteristics, which were compared with the views elicited from students during the discussion sessions (see Table 1).

\section{Evaluation}

The conference method of presenting PDP was evaluated in several ways. The methodology behind this study was phenomenological. We presumed that there is an 'essence to shared experience' (Patton, 1990: 70). We focused on the participants' descriptions of what they experienced and how it was they experienced what they 
experienced. We accessed the information through unstructured and structured surveys, analysing the output of discussion groups, the content of 120 essays, observation and interviews.

The Economics Department also had detailed marking criteria and these provided another source of information. It is argued that the judgements these criteria lead the economists to make illuminate the 'terms through which the devotees of a scholarly pursuit represent their aims, judgements, justification and so on' (Geertz, 1983 in Becher and Trowler, 2001:46).

In this study we wanted to see if we found any evidence to support the prevailing view that there are 'threshold concepts' (such as 'opportunity cost', 'incentives' or the concept of an economic model) for economics students to grasp that act as 'portals' to understanding their subject (Meyer and Land, 2003; Entwistle, 2003). According to Meyer and Land a threshold concept may possess a number of characteristics, it is likely to be (i) integrative, in that it exposes the previously hidden interrelatedness of something; (ii) transformative so that once understood, it produces a significant shift in the perception of the subject; (iii) potentially irreversible, that is, once acquired it is likely to permanently alter the individual's perspective; and (iv) potentially troublesome. (Meyer and Shanahan, 2003:4).

There was some evidence from their essays and the conference itself that the students faced two broader types of threshold concepts: understanding approaches to learning and the need for conceptual understanding.

\section{Results}

\section{What progress did students make?}

At the time of writing it is too soon to assess (if ever we really can) the full impact of the conference on student achievement. We would need to organise a longitudinal study to assess this over several years and be able to separate the effects of multiple influences. However, in terms of PDP, there is evidence from the assignments that progress was made towards independent learning and working with others. There is also evidence that there may be a void in student's awareness of the need for conceptual understanding.

The students' beliefs about desirable characteristics are also shown in Table 1. Initially students were asked individually to list the top characteristics that economics staff were looking for. Then they negotiated their items on group lists, so the right-hand side of Table 1 captures the end of a developmental exercise. Appendix 3 has further details on the sources used to create the list of student perceptions. 
Table 1: Characteristics of a top economics graduate

\begin{tabular}{|c|c|}
\hline Staff view & Student view \\
\hline $\begin{array}{l}\text { INTEREST } \\
\text { - In economics and the subject as it is } \\
\text { now (i.e. the formal/mathematical } \\
\text { presentation of issues) } \\
\text { - In the world around them } \\
\text { - In what motivates people } \\
\text { SKILL } \\
\text { - To master mathematical skills/to cope } \\
\text { with the maths and the statistics/to } \\
\text { translate economic theory into a } \\
\text { mathematical format } \\
\text { - Communication skills: ability to } \\
\text { communicate clearly and succinctly } \\
\text { - Analytical skills } \\
\text { - To work hard/to a regular pattern } \\
\text { Problem-solving skills } \\
\text { CONCEPTUAL UNDERSTANDING } \\
\text { - Tolerance of ambiguity } \\
\text { - A good understanding of the } \\
\text { concepts and procedures of } \\
\text { hypothesis testing } \\
\text { - Some capacity for economic thinking } \\
\text { peripheral issues (to distinguish the } \\
\text { wood from the trees) } \\
\text { (cf Marking criteria: broad knowledge, } \\
\text { ability to focus, analyse, evaluate and } \\
\text { synthesise and to put into context.) }\end{array}$ & $\begin{array}{l}\text { ACTIVE INTEREST } \\
\text { - Clear, deep and profound } \\
\text { understanding of subject } \\
\text { - Ability to apply knowledge } \\
\text { - Knowledgeable. Up to date with } \\
\text { current issues } \\
\text { - Interested in topic } \\
\text { APPLICATION } \\
\text { - Logical } \\
\text { - Accurate and understanding } \\
\text { - Organised } \\
\text { - Analytical, competent intelligent. } \\
\text { Good maths } \\
\text { DETERMINED } \\
\text { - Motivated, enthusiastic } \\
\text { - Determined, challenging } \\
\text { - Committed } \\
\text { - Persistent } \\
\text { SELF CONFIDENT } \\
\text { - Articulate, good personality, } \\
\text { argumentative } \\
\text { - Shows initiative } \\
\text { - Good looking }\end{array}$ \\
\hline $\begin{array}{l}\text { Results of an email survey of Economics } \\
\text { Academic Staff, University of Surrey, } 2006\end{array}$ & $\begin{array}{l}\text { Students' beliefs about what } \\
\text { characteristics staff are looking for in a } \\
\text { top economics graduate }\end{array}$ \\
\hline
\end{tabular}

There was some (but not total) contrast between the two lists. The students believed academic staff were looking for: interest, analytical skills, determination and self confidence. The students had a strong sense of the need for interest in the topic, determination and communication skills (this includes some PDP issues that are process rather than outcome oriented).The issues of conceptual understanding, problem solving and tolerance of ambiguity did not surface in their lists so clearly. 
From this we concluded that there is some evidence that the need for conceptual understanding is a 'threshold concept' for economics students. We have not yet decided how to categorise the student view that economics staff want their graduates to be good looking!

\section{Analysis of student assignments: views on independent learning and working with others}

The assignments revealed a wide disparity in previous experiences of independent learning. Some students said that there was little difference between learning at school and university, except that they had more control over their time, others said that there was a big difference now that they were not being spoon-fed.

The assignments also reflected issues about self motivation. Some students reported a feeling of 'being dictated to', so self motivation becomes even more important. Below are some examples of students' increased awareness of purpose:

'Learning at the university is more real than studying at school, I am aware of where this course is taking me and what it will help to achieve in future. Instead of learning because I have to, I am learning because I want to and I know that I will benefit from it in future.'

'Having fun within the subject is something I feel is necessary to become an outstanding economics graduate. Although admittedly economics isn't a hugely interesting subject, it has its moments, and to capitalise on such moments is very important.'

'The conference really opened my eyes on how much work is expected of me and in the past, even though I have known this, I have maybe not taken my studying as seriously as I should have.'

'During the group presentations of "characteristics of a good economics student" certain features such as "enthusiasm" and "an eagerness to learn more about the subject" were mentioned. Honestly this made me and a few of my friends feel slightly guilty and after the conference we told each other that we needed to "fix up."I certainly need to change my attitude towards studying.'

'However, because my (school) teacher helped me too much, this becomes the hidden trouble in my university life.'

There were also comments that exemplified a more practical and limited (although in one case, admittedly mathematical) attitude: 
'Any economics student must gain 120 credits over an academic year, which is 9 months. It means I have an average of 2.25 days to collect 1 credit.'

'An outstanding economics graduate (assuming ceteris paribus) we imagine to be a person who is to achieve high grades and marks in pieces of coursework and exams.'

There were comments reflecting learning about working with others:

'There is a chance that someone in my group may understand some of the things that I don't and conversely, giving rise to "gains to trade."When a study partner makes me understand something that I previously just couldn't get, then it is an obvious benefit to me. And I also benefit even if I am teaching others. As I explain a concept to my classmate, I have first to process the material in my mind and formulate a coherent verbal explanation.'

'I also thought the conference was good for meeting new people as it is impossible to know everyone on the course... the group work enabled me to meet a few new people that you often see but have never really had a chance to talk (to).'

II rarely work in groups, but during the group discussion about essay techniques when everyone was feeding ideas of each other, I realised that it might not be such a bad thing to meet up with friends regularly to discuss work. A week after the conference I met up with a friend for a while to discuss a topic in statistics that we both found complicated. We talked through examples together and finally figured out how to use the formulas. I think that regular group work would certain benefit me as it is a good way to keep each other motivated.'

These comments suggest that meta-learning had taken place, that there was some increasing awareness amongst these students of the need to understand how they learned and to direct that learning.

\section{Economics staff: outcomes}

Findings from the conference fed back to the staff gave them a better understanding of student views. Staff also commented on the helpfulness of the data collected on the specific areas where students needed more help (see Appendix 3, Table 5). 
The main outcome for the economics staff was that they gained confidence to take on board PDP themselves the following year. They have now proposed to embed PDP in existing modules and to create a system for personal tutors to ensure that students have completed skills self assessments and prepared their curricula vitae.

The list of skills required for top graduates that emerged from the email survey of academic staff in the Economics Department (shown in Table 1) may be generic to all students, and further research is needed to assess this.

Unifying and protecting the discipline was an interesting thread to come out of this commentary - perhaps this need is particularly felt in a discipline that has so many boundaries with adjacent subjects?

\section{What central support is helpful?}

The central academic support team found that we needed to take a step back and look at what would enable academics to feel confident in their skills in moving outside the familiar concepts of teaching their specific disciplines, identifying the barriers and what facilitations would be helpful to academics introducing PDP. A range of support could be offered including: workshops on PDP for academic staff, providing case studies of good practice, researching and designing suitable activities, co-teaching, providing support and suggested frameworks for tutoring, workbooks for students and e-portfolio development.

\section{Conclusions}

The overall question at the beginning was whether aspects of pedagogy within economics affected the way that academics chose to deliver PDP. There were further questions about how we could support economics staff in deepening their understanding of PDP and enable them to deliver it effectively to their students.

The conclusion is that economics staff's attitudes to PDP were driven by discipline pedagogy. They were aware of the short-term opportunity costs of investing staff time in delivering PDP, but wanted to explore ways to make it usefully available to their students. They used economic principles to make their decisions (economies of scale and opportunity cost). This rationale might have masked a general awkwardness with the subject, but the delivery of a PDP for their first-year students in 2006 was recognised as a welcome intervention.

The central academic support unit took the opportunity of creating a conference to do more than 'teach skills'. At least half of the programme was about reflection and meta-learning. Senior members of economics staff introduced and then observed 
the conference, participating when they felt it relevant to provide a discipline focus. Post-graduate economics students actively supported the small group working.

There was evidence from the assignments of some meta-learning. There was also evidence that some students considered themselves advanced in study skills, and that there was little more for them to learn. A more detailed conference evaluation is in Appendix 3.

In summary, it could be argued that the way that the Economics Department chose to deliver PDP and the fact that it chose to do anything at all, were indicative of some of the prevailing 'economics tribe' values. Allen (2002) warned that the logical conclusion of PDP will herald a change in the way we teach and the way our students learn. He reiterates QAA's observation that the wider adoption of PDP will require a 'cultural change and changes to the curriculum, student support and guidance systems, and quality assurance procedures' (QAA Guidance on HE Progress Files). Whether the embedding of PDP in modules and enhanced personal tutoring leads to Allen's 'revolution' is yet to be seen.

The conference idea was experimental. Evaluation shows that it was highly successful. All the stakeholders gained (economics staff, students and the central academic support unit). However central resourcing was not available to repeat the idea. Moreover PDP became a requirement of all departments and the Economics Department has decided to deliver PDP in future through tutorials and activities embedded in existing modules.

Other departments in Surrey have chosen to deliver PDP through 'light touch' tutorials, through individualised workbook sessions or through taught modules, and at the time of planning this conference, one or two departments were not actively considering PDP at all.

Consistent with expectations of the economics tribe, we found evidence of using the principle of 'opportunity cost' to identify the model that would provide maximum development opportunity for the students at a minimum additional cost of academic staff time. It may also be that using terms the discipline is familiar with to introduce change helps to facilitate that change.

There are reasons why outsourcing PDP may not be the most appropriate way of delivering it. Firstly outsourcing the teaching could lead to the attitude identified by Peters that can arise if PDP is outsourced to some 'learning support ghetto... if the staff don't value the process then why should I?' (Peters in Allen, 2002: 18). Secondly using staff outside the discipline to deliver PDP may compromise the disciplinary point of view to the detriment of the student. In the long run, some 
co-operation may be optimal whereby outsourced skills experts and discipline-based staff work together to provide targeted PDP.

There was some evidence that economics is defined and bound by its seminal textbooks and as a subject seeking to 'mark out its territory' this is important to it. There was alignment between the academic staff requirements and their marking criteria and some alignment of these with student perceptions. Broad knowledge, the ability to analyse, synthesise and put into context are all part of the economics department's marking criteria. Both staff and students recognised this. Finally we found a growing awareness of the need to improve students' mathematical skills. The discipline of economics increasingly shares one of its frontiers with maths.

We also found evidence pointing towards the proposal that 'conceptual understanding' could be a threshold concept for the students. If this is so, it is another indication that somehow this territory needs to acknowledge the importance of metacognitive activity for the student. It is early evidence for economists that there is more to PDP than just a moral belief that we ought to be doing it (Jackson, 2001). Allen (2002) acknowledges that there could be particular problems about introducing PDP particularly at level/stage 1, partially because of the peripatetic nature of teaching and partially because of the differing levels and requirements within PDP itself. This paper suggests that in this one instance in 2006 at least, he was right.

There are several questions for further research. Further research into the definition of 'conceptual understanding' would be helpful. It would also be helpful to understand the barriers that academic staff face when dealing with personal development skills - are these greater for those in hard-pure subjects in researchled universities?

Future research could also compare attitudes to PDP between teaching and research-based universities. It is interesting to note that a post-92 University (University of West of England, where the PDP section of the Economics Handbook originated) had already successfully introduced PDP for first-year economics students. 


\section{Appendix 1: Surrey Skills Statement}

\section{A) Research Skills and Techniques - to be able to demonstrate:}

1. the ability to recognise and validate problems

2. original, independent and critical thinking, and the ability to develop theoretical concepts

3. a knowledge of recent advances within one's field and in related areas

4. an understanding of relevant research methodologies and techniques and their appropriate application within one's research field

5. the ability to critically analyse and evaluate one's findings and those of others

6. an ability to summarise, document, report and reflect on progress

(B) Research Environment - to be able to:

1. show a broad understanding of the context, at the national and international level, in which research takes place

2. demonstrate awareness of issues relating to the rights of other researchers, of research subjects, and of others who may be affected by the research (e.g. confidentiality, ethical issues, attribution, copyright, malpractice, ownership of data and the requirements of the Data Protection Act)

3. demonstrate appreciation of standards of good research practice in their institution and/or discipline

4. understand relevant health and safety issues and demonstrate responsible working practices

5. understand the process for funding and evaluation of research

6. justify the principles and experimental techniques used in one's own research

7. understand the process of academic or commercial exploitation of research results

\section{(C) Research Management - to be able to:}

1. apply effective project management through the setting of research goals, intermediate milestones and prioritisation of activities

2. design and execute systems for the acquisition and collation of information through the effective use of appropriate resources and equipment

3. identify and access appropriate bibliographical resources, archives and other sources of relevant information

4. use information technology appropriately for database management, recording and presenting information 
(D) Personal Effectiveness - to be able to:

1. demonstrate a willingness and ability to learn and acquire knowledge

2. be creative, innovative and original in one's approach to research

3. demonstrate flexibility and open-mindedness

4. demonstrate self-awareness and the ability to identify own training needs

5. demonstrate self-discipline, motivation and thoroughness

6. recognise boundaries and draw upon/use sources of support as appropriate

7. show initiative, work independently and be self-reliant

(E) Communication Skills - to be able to:

1. write clearly and in a style appropriate to purpose (e.g. progress reports, published documents, thesis)

2. construct coherent arguments and articulate ideas clearly to a range of audiences, formally and informally through a variety of techniques

3. constructively defend research outcomes at seminars and viva examination

4. contribute to promoting the public understanding of one's research field

5. effectively support the learning of others when involved in teaching, mentoring or demonstrating activities

(F) Networking and Teamworking - to be able to:

1. develop and maintain co-operative networks and working relationships with supervisors, colleagues and peers, within the institution and the wider research community

2. understand one's behaviours and impact on others when working in and contributing to the success of formal and informal teams

3. listen, give and receive feedback and respond perceptively to others

\section{(G) Career Management - to be able to:}

1. appreciate the need for and show commitment to continued professional development

2. take ownership for and manage one's career progression, set realistic and achievable career goals, and identify and develop ways to improve employability

3. demonstrate an insight into the transferable nature of research skills to other work environments and the range of career opportunities within and outside academia

4. present one's skills, personal attributes and experiences through effective CVs, applications and interviews

Ref: http://www.surrey.ac.uk/Skills/pgsdp/pgsdp_jss.htm accessed 31 May 06 


\section{Appendix 2}

Table 2: University of Surrey PDP objectives: Level One (The minimum requirement is for a programme to meet one objective from each group)

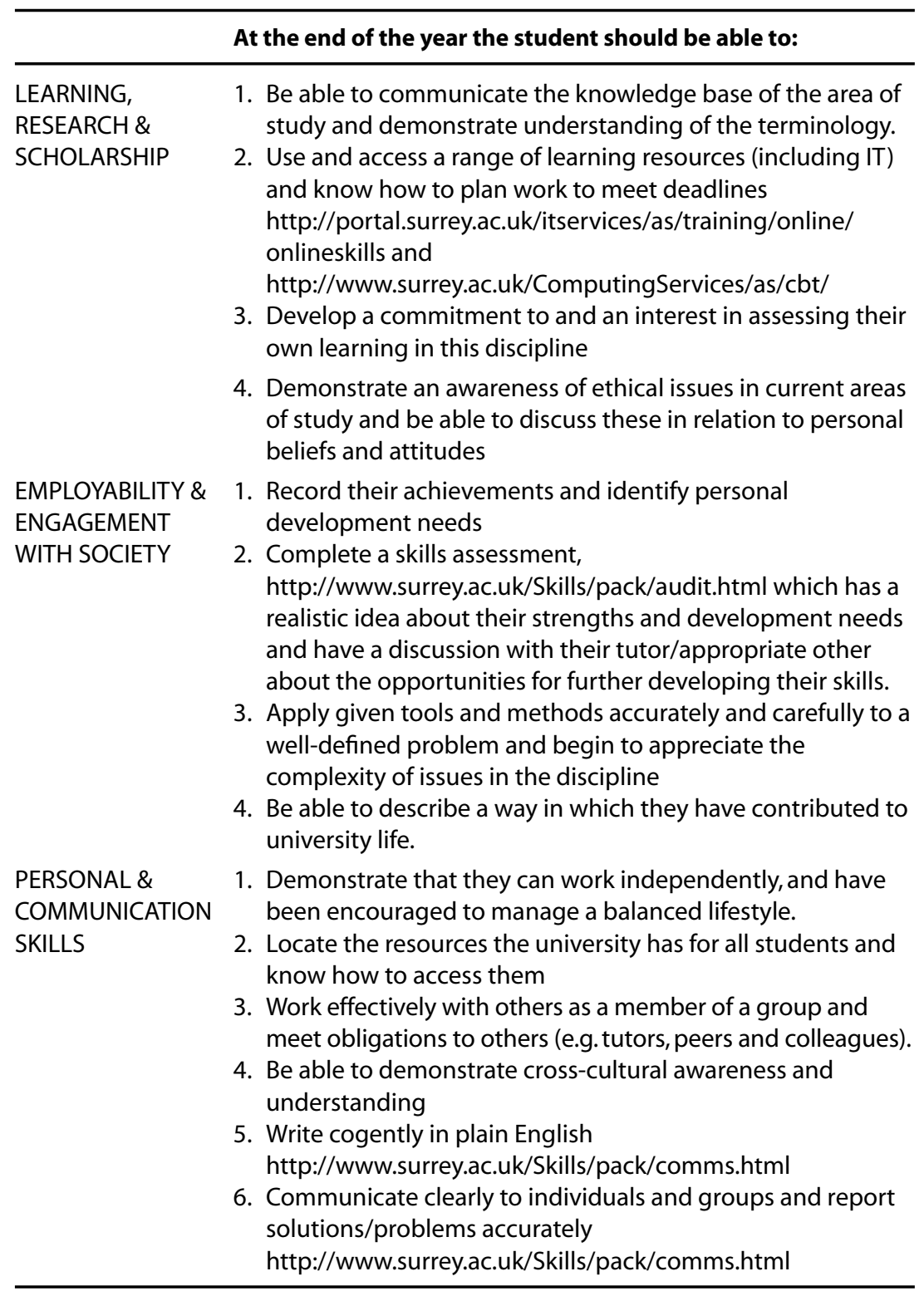


Table 3: University of Sydney graduate attributes

\section{'SCHOLARSHIP: An attitude or stance towards knowledge:}

Graduates of the University will have a scholarly attitude to knowledge and understanding. As Scholars, the University's graduates will be leaders in the production of new knowledge and understanding through inquiry, critique and synthesis. They will be able to apply their knowledge to solve consequential problems and communicate their knowledge confidently and effectively.

\section{GLOBAL CITIZENSHIP: An attitude or stance towards the world:}

Graduates of the University will be Global Citizens, who will aspire to contribute to society in a full and meaningful way through their roles as members of local, national and global communities.

\section{LIFELONG LEARNING: An attitude or stance towards themselves:}

Graduates of the University will be Lifelong Learners committed to and capable of continuous learning and reflection for the purpose of furthering their understanding of the world and their place in it.'

\section{Appendix 3: Developing academic skills for economists - and evaluation}

\section{Summary of feedback on the conference}

\section{Background}

Over two Friday afternoon sessions in 2006, 120 first-year undergraduates were introduced to the importance of developing their goals, identifying their approach to studying and some work on essay writing, under the umbrella of personal development planning.

The method of delivery was innovative both at a macro and a micro level. It was decided to do this in a conference style because there were insufficient economics staff available to help to teach this session. The teaching for both sessions was carried out by Penny Burden and Dr Anne Lee from central student and academic support units, aided by two post-graduate students. The conferences were also attended by Professor Rickman and Dr Heather Gage respectively who both made important contributions to the sessions.

For the second conference we made particular effort to give more information on referencing, because of the comments made by students in response to the session on plagiarism. We also introduced an exercise on assessing sample essays. 


\section{The carrot and the stick}

Attendance at the session was compulsory, but it was intended to make it more attractive by publishing a conference programme, organising displays from various student support groups and providing refreshments. Five credits were available for those students who registered at the beginning, completed the evaluation form at the end of the session, handed in a subsequent information retrieval exercise and completed a reflective assignment.

\section{Summary of findings}

The feedback from the two workshops was similar and the statistical tables (Tables 4 and 5) show a reasonable level of overall satisfaction with the conference.

Table 4: Student evaluation of the conference

Academic Skills Conference Feb 10th

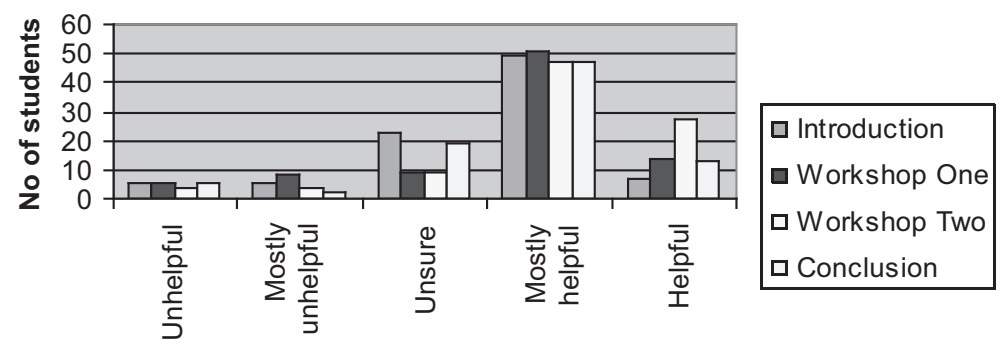

\section{Session ratings}

The overall satisfaction levels show a normal distribution curve for all the sessions: approaches to learning, PDP and academic writing.

Students were also asked to identify what aspects of their studies they would most like further help with. The responses from the two groups have been aggregated in Table 5. 
Table 5: Students' self-assessment of PDP needs

\begin{tabular}{lccccc}
\hline & No need & $\begin{array}{c}\text { Low } \\
\text { priority }\end{array}$ & Unsure & $\begin{array}{c}\text { More } \\
\text { support }\end{array}$ & $\begin{array}{c}\text { Definitely } \\
\text { more } \\
\text { support }\end{array}$ \\
\hline Mathematics for economists & 16 & 22 & 13 & 31 & 21 \\
$\begin{array}{l}\text { Information retrieval from } \\
\text { the library }\end{array}$ & 15 & 26 & 24 & 32 & 7 \\
Surviving exams successfully & 9 & 14 & 14 & 55 & 14 \\
Career management & 1 & 8 & 16 & 49 & 26 \\
Group communication skills & 12 & 31 & 21 & 32 & 8 \\
Time management & 14 & 28 & 19 & 40 & 8 \\
Using ICT & 23 & 33 & 21 & 12 & 2 \\
Study skills & 20 & 28 & 19 & 29 & 4 \\
Presentation skills & 10 & 17 & 22 & 32 & 16 \\
Other & 11 & 5 & 14 & 1 & 3 \\
\hline
\end{tabular}

\section{Note on Table 1}

Table 1 was created from the following list formulated by various student discussion groups. The process used was a snowball technique, whereby individuals make their own lists and then negotiate the inclusion or exclusion of their views in groups of ever-increasing size. The key agreed words are included here to demonstrate the results of a process of content analysis.

$\begin{array}{lll}\text { Organisation } & \text { Attendance } & \text { Hardworking } \\ \text { Show initiative } & \text { Enthusiasm } & \text { Good maths } \\ \text { Clear, deep and profound } & \text { Challenging } & \text { Persistence } \\ \text { understanding of subject } & \text { Accuracy and } & \text { Up to date with current } \\ \text { Ability to apply } & \text { understanding } & \text { issues } \\ \text { knowledge } & \text { Intelligence and } & \text { Dedicated } \\ \text { Motivation } & \text { knowledge } & \text { Competent } \\ \text { Logical } & \text { Articulate } & \text { Enthusiasm } \\ \text { Confidence/enthusiasm } & \text { Good looks, Analytical } & \text { Good personality } \\ \text { Determination } & \text { Commitment } & \text { Interested in topic } \\ \text { Analytical } & \text { Good organisational } & \\ \text { Argumentative } & \text { skills } & \end{array}$




\section{References}

Allen, D. (2002) Personal Development Planning, The Handbook for Economics Lecturers. Economics Subject Centre website http://www.economicsnetwork.ac.uk/handbook/pdp/ Accessed 4.3.07.

Barnett, R. (2000) Realizing the University. Buckingham: SHRE/OU.

Barrie, S. (2006) Graduate Attributes Project http://www.itl.usyd.edu.au/GraduateAttributes. Accessed 31.5.06.

Becher, T. and Trowler, P. R. (2001) Academic Tribes and Territories. Buckingham: Society for Research into Higher Education and Open University Press.

Biglan, A. (1973a) 'The characteristics of subject matter in different scientific areas', Journal of Applied Psychology, 57(3): 195-203.

Biglan, A. (1973b) 'The relationships between subject matter characteristics and the structure and output of university departments', Journal of Applied Psychology, 57 (3): 204-13.

Brennan, J. and Shah, T. (2003) Report on the Implementation of Progress Files. Centre for Higher Education Research and Information. Milton Keynes. http://oro.open.ac.uk/324/ accessed 24.7.2007.

Dearing, R. (1997) Higher Education in the Learning Society. Report of the National Committee of Inquiry into Higher Education (Dearing Report). Norwich:HMSO.

Entwistle, N. (2003) Concepts and the Conceptual Frameworks Underpinning the ETL Project. ETL (Enhancing Teaching and Learning) Project Occasional Report 3. Edinburgh. http://www.ed.ac.uk/etl

Geertz, C. (1983) Local Knowledge. Basic Books in Becher and Trower (2001), Academic Tribes and Territories. Buckingham: SHRE and Open University Press.

Habermas, J. (1971) Knowledge and Human Interests (in Allen 2002). London: Heinemann. Hall, B. (1994) Values Shift. Rockport MA:Twin Lights Publishers Inc.

Jackson, N. J. (2001) Building capacity to support PDP: An Optimistic Vision of Large Scale and Complex Change. LTSN Generic Centre and University of Surrey.

http://www.Itsn.ac.uk/genericcentre/projects/PDP

Meyer, J. and Land, R. (2003) Threshold Concepts and Troublesome Knowledge ETL (Enhancing Teaching and Learning) Project Occasional Report 4. Edinburgh. http://www.ed.ac.uk/etl

Meyer, J. H. F. and Shanahan, M. P. (2003) The Troublesome Nature of a Threshold Concept in Economics paper presented to the 10th European Conference for Research on Learning and Instruction. Padova, Italy.

Meyer, J. H. F. and Shanahan, M. P. (2004) ‘Developing metalearning capacity in students: actionable theory and practical lessons learned in first-year economics' Innovations in Education and Teaching International, 41 (4).

Patton, M. Q. (1990) Qualitative Evaluation and Research Methods. London: Sage.

Perry, W. G. Jn (1970) Forms of Intellectual and Ethical Development in the College Years. USA: Holt Rinehart \& Winston Inc.

QAA Guidelines on HE Progress Files: http://www.qaa.ac.uk/academicinfrastructure/ progressFiles/guidelines/progfile2001.asp (accessed 6.3.2007)

Richardson, P.W. (2004) 'Reading and writing from textbooks in higher education: a case study from Economics', Studies in Higher Education, 29 (4). 


\section{Acknowledgements}

Dr Gage has been especially helpful in working on successive drafts of this article. Professor Rickman and Dr Gage were vital to enabling understanding of the pedagogy that is central to economists, and I am grateful to them and to all the students who participated in this work. Penny Burden, Head of Skills and Personal Development, led the development of the material for the conference and her insight into PDP was invaluable. I would also like to thank the anonymous referees who contributed substantially to my understanding of this work.

\section{Contact details}

Dr Anne Lee

Centre for Learning Development

University of Surrey

Guildford

Surrey

GU2 7XH

UK

\section{Email: a.lee@surrey.ac.uk}

